\title{
The Occasion-Sensitivity of Thought
}

\author{
Tamara Dobler ${ }^{1}$ (1)
}

Published online: 28 December 2017

(c) The Author(s) 2017. This article is an open access publication

\begin{abstract}
On the most common interpretation of occasion-sensitivity what varies cross-contextually is the truth-conditional content of representations. Jerry Fodor argues that when extended to mental representation this view has some problematic consequences. In this paper I outline an approach to occasion-sensitivity which circumvents Fodor's objections but still maintains that the aspect of thought that guides deliberation and action is occasion-sensitive. On the proposed view, what varies cross-contextually are not truth conditions but rather the conditions for accepting a (true) representation as true relative to a practical goal that is pursued on an occasion. I show that although the proposal entails an error theory this theory is not problematic since it is meant to compensate for the over-generating nature of semantic competence, namely, the fact that not all of the representation's truth-makers are conducive to a given contextually salient goal.
\end{abstract}

Keywords Travis cases · Occasion-sensitivity · Truth-makers · Goals $\cdot$ Semantic blindness $\cdot$ Compositionality

\section{Introduction}

Radical contextualists (henceforth, RCs) have recently argued that context-sensitivity is pervasive, that it affects all open class expressions, and that it does so in a way that traditional semantic theories may find difficult to track. ${ }^{1}$ Consider the following example:

Pia, concerned for an impoverished student, asks Max whether the student has a desk. Max replies, 'It depends on what you mean by desk. If you count a door over two stacks of milk crates as a desk, then yes. If not, then, no.' (Travis 2000, p. 3)

The assumption is that in order to answer this question truthfully Max needs to know more about Pia's purposes for asking this question and what she expects from a desk. If she is concerned about whether the student has something to write on, then probably the correct answer is 'yes'. If, however, her purpose makes her expect some high-end piece of furniture made of cocobolo, then probably 'no'. ${ }^{2}$ Insofar as our purposes are extremely variable and unpredictable, so is, the idea goes, the content of our representations.

Tamara Dobler

T.Dobler@uva.nl

1 ILLC, Universiteit van Amsterdam, P.O. Box 94242, 1090 GE Amsterdam, The Netherlands
These and similar cases are typically used to argue that the interpretation of a natural language expression is sensitive to certain factors pertaining to the occasion of use, and so that the compositionally determined meaning of a sentence underdetermines its intuitive truth-conditions. ${ }^{3}$ Some RCs take OS even further: on their view the phenomenon

\footnotetext{
${ }^{1}$ Radical contextualism and moderate contextualism come in many different flavours. Prominent radical contextualists include: Travis (1978, 2000, 2008, 2009, 2011), Searle (1980), Austin and Warnock (1962), Lahav (1989), Moravcsik (1994), Recanati (2004) and Carston (2002). See Recanati (2004) for an exhaustive overview of moderate and radical contextualist positions. See Borg (2010), Cappelen and Lepore (2008) and Pagin and Pelletier (2007) for the relationship between moderate and radical contextualism.

2 This is at least the direction in which the intuitions as regards classifying desks in these circumstances are claimed to go. For some experimental evidence on intuitions concerning Travis cases see Hansen and Chemla (2013).

3 Although occasion-sensitivity (OS) and semantic underdeterminacy (SU) are two very closely related theses, they shouldn't be conflated. OS is a term used (almost exclusively) by Charles Travis to describe a particular sort of context-sensitivity (of representation and belief), namely to occasions on which people are engaged in certain activities and projects, and where certain goals are pursued. SU is a more general thesis about the relation between meaning and truth (propositional content). Part of my argument is that it is possible to maintain that all representation is occasion-sensitive, without presupposing SU, namely, by arguing that a feature of our mental states that is sensitive to what goes on on some occasion is not its content. See also Sect. 2. Thanks to an anonymous reviewer for inviting me to clarify this point.
} 
is more general, applying to any symbolic system including the language of thought (cf. e.g. Travis 2000, 2008, 2011; Recanati 2007). ${ }^{4}$ The idea is that not only natural language expressions but also possibly other types of non-linguistic representation have to be supplemented by additional contextual information in order to be able to determine their contents and predict their effect on behaviour. Thus, in our example, what Pia has in mind and which applications of the concept desk she would allow and which not, which inferences she would licence and which not, depends on other things she believes in or wants to do, besides tokening a certain mental particular.

It is certainly not obvious that, even if OS is true for the linguistic case, it can be generalised in this way to other, non-linguistic representational systems. In Fodor (2003), Jerry Fodor argues against radical contextualism for being committed to the thesis that the content of a simple representation is constituted by the occasion-specific information. His main point is that, construed as a thesis about content, OS is incompatible with strong comositionality (which is 'non-negotiable'). However, not only do we lose strong compositionality by endorsing RC but, when extended to nonlinguistic (mental) representation, OS has some problematic consequences. In particular, if thought were occasion-sensitive in this way, the thinker wouldn't know, in absence of a right context, whether she thinks content A or B when entertaining a given thought. Fodor points out that whilst this kind of uncertainty about others' thoughts is expected where a language (qua a vehicle of communication) is ambiguous, it makes no sense to extend it to the first person case where access to intended meanings is direct and immediate. ${ }^{5}$

In this paper I will try to build a case for the thesis that OS generalises to mental representation, but defending it will require a non-standard interpretation of the phenomenon of OS where what varies cross-contextually is not the representational content of representations. On the analysis of OS that I propose what varies across different occasions are not truth-conditions but acceptance conditions: what is occasion-sensitive is our readiness to accept that a (true) representation is true. In short, if a truth-maker (a property of a possible world) is not conducive to the contextually salient goal, the representation (whose truth-maker this is) won't be accepted as true (by rational agents) on an occasion where this goal is salient. On this view, our intuitions concerning Travis cases are not about truth and truth-conditions

\footnotetext{
${ }^{4}$ Note that this generalised form of contextualism excludes the approach of Carston (2002) and Recanati (2012).

5 Part of Fodor's point is that Mentalese vehicles are supposed to be vehicles of computation not of communication with oneself, not something that needs to be interpreted; so "a thought that disambiguates a statement can't itself be equivocal in the same respect that the statement is" (Fodor 2003, p. 107).
}

but about the acceptance of representations as being true with respect to contextually salient goals. A key feature of my proposal is that the semantics of representations remains classical (as Fodor thinks it should) whilst the sensitivity of our mental states to occasions still plays a central role in explaining rational behaviour (in the spirit of radical contextualism).

The proposed view entails an error theory since it is claimed that, for practical reasons, rational thinkers systematically screen out, and are temporarily blind to, certain truth-makers for a given representation. That is, they refuse to accept as true certain true propositions. I argue that the error theory my proposal ascribes to rational agents is not problematic insofar as it explains their 'truth-maker blindness' by appealing to reasons of practical rationality, in particular, to their intention to successfully achieve practical goals.

The discussion will be organised as follows. In Sect. 2, I introduce Travis cases and the RC interpretation of OS that these cases motivate. In Sect. 3, I discuss Fodor's criticism of RC. In Sect. 4 I propose an alternative interpretation of OS and Travis cases that avoids Fodor's objections. In Sect. 5 I discuss a feature of the proposed account, namely its error theory, and give some reasons as to why it's not supposed to be problematic. I conclude in Sect. 6.

\section{Travis Cases, Semantic Underdeterminacy and Contextualism About Mental Content}

The phenomenon of OS is most commonly illustrated by so called Travis cases (see e.g. Travis 2008), sometimes also referred to as context-shifting arguments: scenarios in which the truth values we intuitively assign to natural language sentences vary across different occasions of use even when sentences contain no obviously context-sensitive expressions or modal operators. RC appeal to these cases to argue that context-sensitivity is a global phenomenon, which affects all open class expressions (including proper names and predicates). Consider the following sentence:

\section{The leaves are green}

The question is whether this sentence expresses a unique proposition, assuming our knowledge of meaning and of referents. RCs argue that (1) does not express a unique thought even when the object referred to in a context is known. Consider a much discussed The leaves are green Travis case:

Pia's Japanese maple is full of russet leaves. Believing that green is the colour of leaves, she paints them. Returning, she reports, 'That's better. The leaves are green now.' She speaks truth. A botanist friend then phones, seeking green leaves for a study of green-leaf 
chemistry. 'The leaves (on my tree) are green,' Pia says. 'You can have those.' But now Pia speaks falsehood. (Travis 2008, p. 111)

The example is meant to illicit the intuition that on one occasion (henceforth, the decorator context), Pia (henceforth, the decorator) says something true when she says that the leaves are green, and on another occasion (henceforth, the botanist context) she says something false whilst uttering the same sentence to her friend (henceforth, the botanist). According to Charles Travis, the variability in understanding what is said by (1), which results in different intuitions as to whether they count as being true, occurs as a consequence of a change in background information, most notably due to a shift in contextually relevant goals and interests.

The standard contextualist analysis of Travis cases, according to which it is content that thus varies, lends support to a more general thesis to the effect that meaning underdetermines truth. This is sometimes referred to as the semantic underdeterminacy thesis (SU). Here are some of its formulations:

What words mean plays a role in fixing when they would be true; but not an exhaustive one. Meaning leaves room for variation in truth conditions from one speaking to another (Travis 2008, p. 94).

[The] meaning encoded in the linguistic expression... underdetermines the proposition expressed (what is said) (Carston 2002, p. 20).

Whilst $\mathrm{SU}$ is a general thesis about the relationship between standing meaning and truth, OS is a more specific thesis about which contextual features our representations are sensitive to: i.e. to occasions on which certain goals and interests are in play. One of my aims in this paper is to show that that it is possible to defend OS without endorsing SU; on this approach, a feature of our mental states that is sensitive to what goes on on some occasion is not its content.

Travis cases are typically used to argue that the interpretation of natural language expressions (i.e. the content they express, their contribution to truth-conditions) is sensitive to some features of occasions (in the way in which this also implies SU). However, for some theorists, the phenomenon is more general, affecting any symbolic system of representation including the language of thought (LOT). The main idea is that not only natural language expressions but also possibly other types of non-linguistic representation would have to be supplemented by additional contextual information in order to be able to predict their effect on behaviour.

Not all radical contextualists think that SU and OS generalise to all symbolic systems. Carston (2002) for instance maintains that:

Mentalese sentences do not underdetermine their truth-conditional content, they are not context-sensi- tive, they are eternal. Given the formality constraint, Mentalese sentences and phrases must be unambiguous; that is, there are no elements of form which have several distinct semantic values, as do 'bank' and 'visiting relatives' in English. (Carston 2002, p. 75)

Although presented as an opposition to Fodor (2003) arguments against contextualism, Recanati's modulation theory is similarly not incompatible with Fodor's position on the semantics of thought. The modulation approach presented in Recanati (2012) is a contextualist theory concerning how contents of natural language expressions are determined; pragmatic modulation doesn't apply in the domain of mental representation and in this sense that natural language expressions have modulated contents doesn't entail that mental representations do. Like Carston's theory of ad hoc concepts (2002, 2010, 2012), Recanati's modulation theory targets the nature of the relation between linguistic expressions and concepts they express (the claim is that this relation is not stable and context-independent) rather than the nature of the relation between LOT vehicles (mental representations) and their contents.

However, some theories (Recanati 2007; Travis 2000, 2008, 2011), in addition to claiming that natural language expressions have context-dependent contents, also assume that non-linguistic (mental) representations (qua vehicles) lack stable contents. For Recanati (2007) it is "hardly controversial... that there are thoughts (in the vehicle sense) whose truth-conditional content depends upon the context, just as there are sentences whose truth-conditional content depends upon the context" (Recanati 2007, p. 15). Similarly, for Travis, "thoughts... lose their claims to have some one semantics intrinsically, and to be immune to interpretation" (Travis 2008, p. 129). Importantly, neither Travis nor Recanati think that thought-contents (truth-conditions) are context-sensitive or ambiguous; the claim is only that which content a Mentalese word or sentence expresses (provided these are well motivated) is not independently fixed but it depends on context.

\section{Fodor's Critique of RC}

Although it is not entirely clear whether Fodor's arguments in Fodor (2003) are meant to apply both to the case of linguistic and mental representation, it seems that the primary target is precisely the general thesis defended by Travis $(2000,2008)$ and Recanati (2007) to the effect that any symbolic representation could have context dependent content. ${ }^{6}$ Fodor's critique of RC is given in the context of

\footnotetext{
${ }^{6}$ Thanks to an anonymous reviewer for prompting me to clarify which version of radical contextualism is the most likely target of Fodor's arguments.
} 
his defence of the compositionality principle. Fodor construes RC's idea of OS as "an equivocation that can't be resolved" (Fodor 2003, p. 99).

To endorse $\mathrm{RC}$ about natural language is to claim that equivocation is radical and it cannot be resolved by arriving at "unequivocal expressions of finite length" (Fodor 2003, p. 99, ft. 20); instead, context is necessary to determine the meaning of any single expression. However, if we radicalise context-sensitivity in this way, then Fodor thinks we must give up that natural languages are compositional:

if unresolvable equivocation is the general case, then there are no simple representations as the compositionality thesis understands that notion. (Fodor 2003, p. 100)

Fodor's characterisation of compositionality involves a 'highly substantive' constraint. This further requirement concerns the properties of lexical meanings that constitute the input to the composition function: simple concepts that compose into complex ones must have context-independent contents (Fodor and Lepore 2002, p. 58). This is because only if we assume that simple concepts have stable, context-independent meanings we can explain how they make a systematic contribution in the production of complex concepts.

Notice that to endorse RC about natural language and to deny that natural language is strongly compositional need not entail anything about the compositionality of thought. In some of his other works, Fodor himself argues that natural languages are notoriously inexplicit and ambiguous, and therefore not compositional but he still, of course, maintains strong compositionality for thought. ${ }^{7}$ To endorse RC about representation in general is to claim that "there are no representations whose content is independent of their context" (Fodor 2003, p. 100). The latter position, Fodor argues, not only violates compositionality but is moreover absurd, because it implies that a thinker can think a thought that is "equivocal-but-for-the-context", which puts the thinker and her interpreter "on all fours" when it comes to figuring out what she meant (Fodor 2003, p. 107). In effect, the thinker wouldn't know, in absence of a right context, whether she thinks A or B when entertaining a given thought. Thus, what Recanati (2007) considers 'hardly controversial' is according to Fodor's analysis 'absurd' ${ }^{8}$ The conclusion

\footnotetext{
${ }^{7}$ In Fodor (2001) he writes: "as a matter of empirical fact, language is pretty clearly not compositional; so it can't have content in the first instance" (Fodor 2001, p. 11).

${ }^{8}$ In the RTM framework, different mental vehicles (particulars) can have the same content (e.g. Water and $\mathrm{H}_{2} \mathrm{O}$ ) but the other way around is not possible. They are ipso facto different vehicles if they token different contents (types). Cf. Fodor 1990, p. 167.
}

Fodor draws from his discussion of $\mathrm{RC}$ is that the content of a mental representation cannot be occasion-sensitive.

My primary concern here is whether there is a way reconcile the contextualist idea to the effect that what a thinker has in mind (and her subsequent behaviour and actions) might depend on the occasion she's in, without incurring the charge of absurdity and, moreover, without giving up on a strong variant of compositionality for mental and for linguistic representation (i.e. where simple representations are taken to have have fixed, context-independent contents). ${ }^{9} \mathrm{My}$ suggestion is that the occasion-specific information may play a role in constituting what the speaker has in mind (i.e. her mental state) and her subsequent behaviour without thereby constituting the content of her mental state.

\section{The Occasion-Sensitivity of Acceptance}

Can we preserve strong compositionality whilst maintaining that information about context is constitutive of what a thinker has in mind and her subsequent behaviour? In what follows I sketch an account on which thought is both strongly compositional and occasion-sensitive.

\subsection{Belief State and Belief Content}

I said above that although Travis cases are formulated in order to show that the interpretation (i.e. content, truthconditions) of NL sentences may differ across different occasions, some proponents of RC take these cases to be also relevant for non-linguistic representation thus showing that what the thinker has in mind is, like her words, occasion-sensitive. Now, it's crucial, I think, how we interpret this generalisation of OS to all representational systems. According to the standard interpretation, which we've seen Fodor criticises, this amounts to saying that the content of a mental representation varies cross-contextually. But this is certainly not the only way to interpret the notion of what the thinker has in mind. What $\mathrm{RC}$ seem to require is that 'what the thinker has in mind' is consciously available to

\footnotetext{
${ }^{9}$ Perhaps the most common way in the current literature to argue for the compatibility between context-dependence and compositionality of natural languages is to relax the context-independence constraint so that although we lose strong compositionality we still preserve the weak variant. Pagin and Pelletier (2007), Pagin (2005), Recanati (2012), Dekker (2014), Lasersohn (2012), Predelli (2005), Szabó (2010), Buekens (2005), Westerståhl (2012) all propose that the input to the composition function could be the meanings that have undergone pragmatic processes of modulation or free enrichment. Formally speaking, compositionality works just as well with contextdependent, or modulated meanings, and so the context-independence constraint is not mandatory for compositional semantics. Notice that it is not obvious how this weakening strategy would work for mental representation.
} 
her ${ }^{10}$ and that it plays a role in her planning and decisionmaking processes (i.e. that it figures in her intended course of action) - and RC claim that this property of the agent's cognition is occasion-sensitive. However, I contend that these requirements can be met without endorsing a further claim to the effect that the notion of what the speaker has in mind corresponds to the content of her mental representation which need not be consciously entertained by the agent (at least not in its entirety) when the mental representation is tokened. Let us try to explain this proposal in more detail by appealing to Fodor's distinction between belief-state and belief-content.

Fodor's argument for the thesis that "there is nothing at all to meaning except denotation" (Fodor 1990, p. 161) relies on distinguishing between thought content-which he assumes is a bearer for names, and a property for predicates-and other components of a state that a thinker is in when she tokens the thought that $p$. Although Fodor is not explicit about this, I think it's safe to assume that the extensional content of the whole thought (qua mental representation) is a set of (partial) worlds where the proposition the thought expresses is true. Other factors besides content, notably a vehicle and a functional role, contribute to determining which belief state the thinker is in, including how being in this state will figure in her plans and her subsequent course of action. Thus, a belief state with the same content can result in different behaviours and inferences if these other factors are different. ${ }^{11}$ Moreover, Fodor's framework does allow that, unlike content, these other factors that enter into belief individuation are occasion-sensitive. ${ }^{12}$ The bottom line is that "you don't predict behavior (just) from the content of concepts (i.e. from their semantics; i.e. from what composes). You predict behavior from the galaxy of beliefs, desires, hopes, despairs, whatever, in which the concepts are engaged" (Fodor 2008, p. 87). On this view, it is incorrect to assume that only content explains behaviour and inference because "people act out of their whole state of mind" (Fodor 2003, p. 103).

\footnotetext{
10 See Recanati (2004) on the availability principle as a criterion of intuitive truth-conditions.

11 He thus writes "It seems to me plausible that you can have two beliefs with the same object and the same vehicle, where the difference between the beliefs comes from differences in the inferential/ causal roles that the vehicles play. This happens when, for example, two guys who use the same vehicle to express the same content differ in their background theories;" (Fodor 1990, p. 167).

12 Fodor writes, "in my view, the most that the standard skeptical arguments about content actually show is that belief individuation is plausibly pragmatic and holistic . But this implies nothing about the individuation of content unless you accept 'different beliefs $\rightarrow$ different propositional objects'. Which I don't.” (Fodor 1990, p. 174). See also Fodor (2003, p. 104.)
}

\subsection{Truth-Makers}

Before I continue with the explanation of how Fodor's distinction bears on OS, I need to define a notion that will be important for the present discussion: it's the notion of $a$ truth-maker for a representation $R$. Let us call the set of possible worlds where $\mathrm{R}$ is true the truth set for $\mathrm{R}$. If $\mathrm{R}$ expresses the content that the leaves are green, then the truth set will contain different subsets of worlds: one where the leaves are naturally green, other where they are painted green, yet another where they are moldy green etc., including all their possible combinations. Call each of these subsets of the truth set a truth-maker for $R$ (or, equally, a way for $\mathrm{R}$ to be true). ${ }^{13}$ The union of all truth-makers for $\mathrm{R}$ corresponds to its truth-set, i.e. the set of worlds where $\mathrm{R}$ is true. Importantly, whilst the leaves being painted green and the leaves being naturally green are each a truth-maker for this content, they are nonetheless distinct truth-makers (i.e. they make the content of The leaves are green true in different ways). Now that we defined the notion of a truth-maker let us see how it can help with OS.

Assume that the botanist and the decorator from The leaves are green Travis case both stand in the relation (of believing) to the same proposition that the leaves are green. Correspondingly, the proposition their belief expresses is true just in case the leaves are green. We are also told in the example that the leaves are painted green but are naturally red. Furthermore, whilst (in the botanist context) the artist is happy to accept this state of affairs as a truth-maker for what she has in mind, the botanist isn't. However, doesn't this make the botanist simply incorrect in rejecting the decorator's assertion? Are our intuitions here wrong? Suppose we grant that the botanist $i s$ wrong and what the decorator says (in the botanist context) is true. What are the consequences of this assumption?

Recall that the botanist plans to conduct an experiment; furthermore, she believes that if the leaves are green, then she can conduct her experiment. Then, once she finds out that the leaves are green (is true) she should be able to successfully act. But she can't. So the fact that the belief is true (where truth is defined as an absolute notion) is not a sufficient guide to action as this case indicates. Assuming that if it is true (on one occasion) that the painted green leaves are green then it's always true, it is necessary to explain why it nevertheless seems correct not to

\footnotetext{
${ }^{13}$ In Yablo (2014) a truth-maker for $p$ is, formally speaking, a set of possible worlds. Here also a truth-maker is a set of possible worlds, only I allow that an atomic proposition $p$ can have more than one truth-maker: $p$ can be made true in more than one way. Although the union of truth-makers of $p$ forms a cover over the truth-set of $p$, the two sets (the set of $p$ 's truth-makers and $p$ 's truth set) are not identical.
} 
accept it as true (on an occasion where the salient goal is to conduct an experiment). I will attempt to do this in the next section. Namely I will suggest that besides belief content (and other factors that Fodor appeals to) our belief states include (occasion-specific) goal-conduciveness maps-hypotheses about what it takes to achieve certain contextually salient goals, including whether a particular truth-maker is conducive or not to the goal. The main effect of the presence of a goal and goal-conduciveness map in a belief state is to temporarily blank out those truth-makers which are not conducive to a given goal. In other words, whenever a certain goal is present, only part of representational content is consciously available to the agent.

\subsection{Truth and Acceptance of Truth}

Based on the story I've told so far although the content of the proposition that the leaves are green is the same for anyone who relates to it, the belief state they are in when tokening that thought may be different for any two thinkers (or the same thinker on different occasions) insofar as their background theories differ. However, a belief is true whenever its content is true, when the proposition the thinker relates to is true. Thus, if belief content is indeed the same for the botanist and the decorator, what they believe and what they say should be true of the same state of the world, and, if true, it should be true regardless of other factors. Although our story predicts that what the decorator says to the botanist should be true (because, by assumption, painted green leaves are green), intuitively this is not accepted as true. Furthermore, according to our story, if they token the same proposition they should agree about whether what they believe is true; but, intuitively, they don't. Is there a way to reconcile our intuitions concerning Travis cases and the Fodorian story about content individuation.

I think this is possible under the assumption that what our intuitions track in Travis cases is not truth-conditions but acceptance conditions, namely the conditions for accepting a (true) proposition as true. With this distinction in mind, the proposition that both the decorator and the botanist relate to, if true, is true for both and true of the same state of the world. Still, there are some (pragmatic) constraints concerning when this fact, i.e. that the proposition is true, is (or ought to be) accepted. On the occasion where an experiment is to be conducted the fact that the proposition is true is not accepted (correctly so). On the other hand, it is accepted that the proposition is true on those occasions where whether they are naturally green or not is irrelevant. Thus, if the goal is to make a decoration (where natural greenness doesn't play a role) we are prepared to accept the proposition as true; if, however, it matters for the success of the goal that the leaves are naturally green, then the fact that this (i.e. the leaves being painted green) is also a truth-maker for the proposition is not recognised and thus the truth of the proposition is not accepted. In general, whenever we are presented with a context in which a particular practical goal is salient then our intuitive acceptance of truth (of a proposition) is judged relative to that goal.

\subsection{Goal-Conduciveness Maps}

On this story, what we plan to do next, which practical projects we are pursuing, determines whether or not we would recognise a truth-maker as truth-maker and whether we would accept that the proposition (expressed by linguistic or mental representation) is true at a world which instantiates that truth-maker. This narrowing down of the set of truth-makers for a proposition to those that would support a given, occasion-variant goal is a consequence of the fact that not all truth-makers are goal-conducive. Immediate goals and interests, on this view, guide the activation of a background theory, where the choice of a theory varies depending on which goal we pursue. For instance, the theories about the greenness of leaves when making experiments and when making decorations may be quite different.

The acceptance conditions of a (true) proposition (as true) are determined relative to what I call goal-conduciveness maps. More specifically, for each goal there is a goal-conduciveness map on the basis on which rational agents can determine whether a particular truth-maker for the proposition is acceptable as such or not. The idea is that a conduciveness map for the goal $g$ will contain the specification of the conduciveness value (conducive, not conducive) of a truth-maker for that particular goal. Only if a truth-maker for $p$ is conducive to the goal of context $g$, the proposition $p$ expressed by linguistic or non-linguistic representation is accepted as true by rational agents at a world which belongs to that truth-maker.

Definition (truth-conditions) The representation R (linguistic or non-linguistic) expressing the proposition $p$ is true at $w$ iff $p$ is the case at $w$.

Definition (acceptance-conditions) The representation $\mathrm{R}$ expressing the proposition $p$ is accepted as true at a world $w$ relative to the goal of context $g$ iff the following two conditions are satisfied: 
i. $\quad p$ is the case at $w$

ii. $w$ belongs to a truth-maker which is conducive to the goal of context $g$

On this view, whilst truth-conditions are determined compositionally, competent speakers/thinkers are nonetheless reluctant to accept as true on one occasion what they accept as true on another because the conduciveness value of a truth-maker may vary. On the proposed view, it is acceptance conditions that are determined relative to contextual information, whilst truth-conditions remain absolute. Notice that a necessary condition for accepting a proposition is that the proposition be true. Thus, a proposition cannot be accepted to be true without being true, but it can be true without being accepted as true (relative to the goal $g$ ) by rational agents. Furthermore, in the limiting case where every truth-maker of $p$ is also conducive to goal $g$, its acceptance conditions will correspond to its truth-conditions.

Although the proposed framework explains the data presented in Travis cases, it cannot account for so called cases of 'loosening' or 'broadening' where a sentence is assumed to be false but its utterance in a context is nonetheless acceptable. ${ }^{14,15}$ What is more, the theory seems to make wrong predictions for negative sentences and cases of loose use. In the next section I explain how some of these cases can be handled in the present framework and why some of them are not accounted for.

\subsection{Figurative Use, Loose Use and Negation}

On the approach I presented above, to be accepted as true a representation must be true: that a representation is true (in a weak sense) is a necessary condition of acceptance. However, whilst this seems to capture well the data presented in Travis cases, it doesn't seem to explain other data, notably the cases of figurative use (including metonymy) and loose use where a sentence is literally false but its utterance in a context may be accepted as true. Moreover, the account seems to make wrong predictions about negation where again the sentence could be literally false but still accepted as true in a right context. Consider following examples:

\section{Mary is a bulldozer}

3. The city is asleep

4. Everyone passed the exam [said in the context where all the students in the class passed the exam]

\footnotetext{
14 Thanks to an anonymous reviewer for pointing out this potential gap in the framework and for inviting further discussion. See Sect. 4.5.

15 For discussion of the phenomenon of broadening see Carston (2002), Recanati $(2004,2010)$.
}

5. France is hexagonal

6. The cookie is round

7. Mary lives in Paris [said in the context where she live in Issy-les-Moulineaux, just outside Paris city limits]

8. You won't die [said in the context where the child's got a little cut]

9. The leaves are not green [said in the botanist context of the non-naturally green leaves]

Sentences (2)-(9) are usually taken as examples of the process of loosening, widening, or broadening of the concept encoded by a lexical item. This process is opposite to that of narrowing or enriching the lexically encoded concept, which is captured in Travis cases. ${ }^{16}$ Do these cases where the denotation of a concept is extended rather than restricted present a problem for the current account? There are a few things to say in defence of the proposed framework. First, the theory of OS I proposed above explains how we can preserve a classical (albeit weak) semantics for representations whilst respecting intuitions about Travis cases. This reconciliation is possible if we distinguish between the content that representations express (that determines when a representation is true) from how conducive to the goal part of its content is (that determines when a representation will be accepted as true). Now, as it has been argued (Sperber and Wilson 1986; Grice 1975), in some cases of loosening (figurative use, metaphors, tropes) the content that the linguistic representation encodes is not the content intended to be communicated, a fortiori, not the content of a mental representation associated with the utterance of that sentence in a context. ${ }^{17}$ Sentences (2) and (3) are clearly examples of such (non-literal) uses of natural language, where thought contents are clearly different from the literal meaning of these sentences. Similarly, in (4) although the form of non-literalness is rather different (i.e. a restricted domain of quantification), still the lexical item 'everyone' is not intended in a literal way denoting everyone in the universe. ${ }^{18}$ By contrast, in Travis cases it is not so obvious that the literal content of a sentence is supposed to diverge from the content of a mental representation: minimally, there is no similar intention to use the sentence

\footnotetext{
16 As Carston (2010) points out, "the pragmatically derived [ad hoc] concept may be more specific or more general than the encoded concept; that is, its denotation may be either a proper subset or a superset of the denotation of the linguistically encoded concept, or it may be a combination, both extending the lexical denotation and excluding some part of it" (Carston 2010, p. 242).

17 I depart from the standard Gricean and relevance theoretic approach in that loose use is here not treated as a case of figurative use.

${ }^{18}$ It would be felicitous to continue with 'But I don't mean literally 'everyone!'. Furthermore, although a form of context-dependence, quantifier domain restriction (like indexicality) is not necessarily a form of dependence on contextual goals.
} 
figuratively and express something non-literal. The point is that whilst non-literal use is a good example of the concept expressed being different from the encoded concept, the phenomenon in Travis cases lends itself to a different explanation where the concept expressed coincides with the lexically encoded concept. Unlike the latter phenomenon, non-literal use is beyond the scope of the current proposal.

However, not all cases of loosening are cases of nonliteral use. Sentences (5)-(7) are, arguably, the cases of literal use. How is the proposed account supposed to deal with them? Notice that (5)-(7) are examples of loose use where an individual can be said to have a property expressed by a predicate only in a loose way or not strictly speaking. My suggestion is to treat these cases contrary to how they have been sometimes treated by semantic invariantists. Namely, whenever an individual $a$ possesses the property expressed by $\mathrm{F}$ in a loose way or not strictly speaking, the sentence $\mathrm{F} a$ will come out true. ${ }^{19}$ On this approach, (5) will be true in the geography context and in the maths context, however it won't be accepted as true in the latter context because of the goal which presupposes a higher standard of precision. Similarly (6) and (7) will be true just in case a given property can be predicated in a loose way of a given individual; still there will be contexts where these won't be accepted as true (because of goals that imply raised standards of precision).

Finally, let's turn to the case of negation. Like loose use, negative sentences are clearly cases of literal language use, so the proposed framework should be able to explain their sensitivity to occasions. Recall that the main logical property of a negative sentence is that its content is true just in case the content of a negated sentence is false. ${ }^{20}$ Thus, whenever the accepted content of a negated (i.e. positive) sentence is restricted (because of a goal) the theory predicts that the accepted content of a negative sentence is loosened. In other words, there is a reverse entailment relation between truthconditions and acceptance conditions of negations, such that from the fact that a negative sentence is accepted as true one cannot conclude that it is true (note that the opposite is the case for positive sentences) ${ }^{21}$ On this view, the contents of (8) and (9) are both false (although they are accepted as true in the contexts specified above) because their negations (i.e. positive sentences) are literally true (albeit not accepted as true in these contexts).

\footnotetext{
${ }^{19}$ For a similar account of loose use see Asher (2011) and Partee (2010). On Asher's account the denotation of a loosely interpreted predicate doesn't change but rather there is a loosening of the predication relation to the effect that "stone lions aren't strictly speaking lions, but they are closer to lions on the relevant metric (here shape) than any of the alternatives suggested by lion" (Asher 2011, p. 308).

20 This property is the basis for the law of non-contradiction.

${ }^{21}$ For a similar point on the context-sensitivity of negations see Schoubye and Stokke (2016).
}

\section{The Error Theory}

On the proposed view, what our intuitions concerning Travis cases and OS track are not truth conditions but rather the conditions for accepting a representation as true. Whether a representation is acceptable or not as true is decided relative to the goal-conduciveness value of its truth-maker, and this value varies cross-contextually. One important ramification of this proposal is that practical considerations can trump what semantically would be evaluated as true (and may be accepted as true on other occasions). As a consequence, rational thinkers are saddled with a particular (temporary) form of blindness to certain truth-makers which they judge not to be conducive to the goal they pursue on a given occasion. Every such theory incurs a burden of accounting for the fact that it seems to ascribe to competent speakers/thinkers a form of semantic incompetence. In this section I intend to address this aspect of the current proposal.

\subsection{Between Contextualism and Invariantism}

Semantic blindness has been a prominent topic of the debate in epistemology concerning context-sensitivity of knowledge and knowledge ascriptions (cf. Hawthorne 2004; DeRose 2006; Stanley 2005; MacFarlane 2005; Montminy 2009; Rancourt 2015). This is not a place to examine the arguments for and against different positions on the role of context in epistemic sentences; my reference to this debate has a sole purpose of establishing whether the present proposal entails a problematic sort of error theory.

It has been claimed that both contextualism and invariantism about knowledge and knowledge ascriptions saddle competent speakers with a sort of incompetence which appears to be incompatible with their ability to successfully communicate and competently use language. Thus, it has been argued that the contextualist theory cannot explain the intuitions about retraction and disagreement since the competent speakers fail to acknowledge the apparent context-sensitivity of knowledge claims and instead behave as invariantists (see e.g. Hawthorne 2004). On the other hand, contextualists claim that the sort of blindness invariantists ascribe to competent speakers is even more problematic insofar as, on the invariantist view, either the sceptic or the ordinary speaker must be saying something false (if the other is saying something true) despite knowing all the relevant contextual facts which position entails that "in some contexts at least, ordinary speakers lack access to the conventional meaning of knowledge sentences [and]... are sometimes blind to the truth conditions of knowledge sentences" (Montminy 2009, p. 652). This type of error, the contextualists maintain, is much more troubling than the one the contextualist theory predicts. 
The theory I proposed in the previous section is a mix of invariantism and contextualism: it maintains that the truth-conditions of linguistic and non-linguistic representations are invariant but also that their acceptance conditions vary cross-contextually. So it incurs error theories that afflict invariantism and contextualism. That is, on the proposed view, the competent speakers/thinkers are blind to the truth-conditions of their representations and, moreover, they are blind to the fact that acceptance conditions are not invariant. Is this a problem for the current proposal?

\subsection{Blindness to Truth}

Let me first address the error entailed by the invariantist aspect on my proposal, namely the idea that competent speakers/thinkers are blind to the truth-conditions of their sentences or thoughts. Following Fodor, I have argued that in order to preserve strong compositionality representational contents cannot be occasion-sensitive, and if content just is denotation, that means that the set of truth-makers for a given representation is invariant. Nonetheless, when presented with Travis cases we seem to intuitively pair different truth-makers with the structurally same representation, which suggests that their content varies crosscontextually. I have argued, however, that this interpretation of the cases is not mandatory: when presented with different scenarios what we intuitively evaluate is whether a representation is acceptable as true given the salient goal rather than whether it is true. Since the fact that a representation is true is not sufficient to support a particular course of action (e.g. the fact that the leaf is green is not sufficient to support a botanical experiment), we accept as true the representation which is not only true but also apt to support a given course of action (i.e. which is goal-conducive). Thus, although our semantic competence plays a necessary role in communication, planning, and action, it still over-generates and is thus not always practically useful. The theory predicts that there is a practical need for overgenerating semantic competence to be pragmatically constrained. Accordingly, the alleged 'incompetence' my theory ascribes to the speaker/thinker is necessitated by the fact that she also ought to be a competent and successful agent.

It's important to note that, on this view, a competent speaker/thinker is not blind to truth-conditions only in some contexts but not in others, which is what epistemic invariantism predicts. I maintain that she is blind to semantically determined truth-conditions whenever a salient practical goal is present which may place additional constraints on the acceptance of her representation as true. Hence, it is in any context in which a given course of action is to be taken that makes the speaker/thinker biased for or against certain truth-makers. Invariantism here doesn't concern what we have in mind (or what we say) when we make plans to act but what we would be prepared to recognise as a prospective truth-maker in abstraction from any particular interests and goals.

\subsection{Blindness to the Context-Sensitivity of Acceptance}

Another form of blindness the current account ascribes to the speaker or thinker concerns the inability to recognise that contextual factors play a role in determining acceptance conditions and that these conditions vary cross-contextually. A common charge against the epistemic contextualist is that her theory predicts that the competent speaker should realise that she actually doesn't contradict her interlocutors, that there is no real disagreement, since they each express different contents. Still, the speakers behave as if there is a real disagreement. Similarly, if contextualism were true, the competent speaker should not retract that she knows that $p$ in face of raised standards of knowledge. Yet she does. So, whilst the contextualist theory predicts that semantic competence entails recognition of the role that context plays in determining content, competent speakers actually behave like invariantists, namely, as if context plays no role whatsoever in what they say and think.

On the current proposal, context indeed plays no role in determining content (truth-conditions). Namely, the theory I defend predicts that the decorator says something true on both occasions in The leaves are green Travis case-its being accepted as true in the decorator context entails its truth. But I have suggested that our intuitions about Travis (and other similar) cases are not judgements concerning truth-conditions since these cases feature contextually salient activities and goals. Valuations in Travis cases are instead about acceptability of true representations as true. Accordingly, although the decorator says something true in the botanist context her utterance ought not to be accepted as true. Now if acceptability is indeed context-dependent, this fact should be transparent to competent speakers, but the running objection goes that this isn't so. Namely, we behave as if what we accept as true on one occasion should always be acceptable (and perceive ourselves as disagreeing with our interlocutors).

I think it isn't difficult to explain this sort of practically motivated blindness to the context-sensitivity of acceptance by appealing to the fact that, on an occasion, the agent is focused on a particular goal and what it takes to achieve it. It is perfectly rational for the botanist in the botanist context where a certain goal is operative not to accept the painted green leaf as being green since her goal otherwise won't be successfully achieved. On the 
assumption that her goal is also the contextually salient goal, ${ }^{22}$ she is correct to think herself to be in a real disagreement with the decorator who incorrectly evaluates this situation to be acceptable as true given this goal (the experiment). Still, the botanist would be correct to retract her judgement of non-acceptance in face of a different goal (were the decorator's goal contextually salient the painted green leaf would be goal-conducive). On the current view, the phenomenon of retraction is explained by the capacity to recognise that other goals may be salient in a context.

I stress again that, on this view, neither the botanist's or the decorator's utterance in The leaves are green Travis case is evaluated for truth. Given that occasion-specific goals are clearly indicated in these examples our intuitions concern acceptability which is decided relative to the salient goal. Whenever a particular goal is not indicated any conceivable way of being $\mathrm{F}$ intuitively counts as being $\mathrm{F}$ and truth-evaluations of the sentence $F a$ depend only on whether $a$ is $\mathrm{F}$, regardless of the way of being $\mathrm{F}$ in which $a$ is $\mathrm{F}$ (as long as $a$ is $\mathrm{F}$ in at least one way). ${ }^{23} \mathrm{In}$ contrast, intuitions about acceptance of $F a$ depend not only on whether $a$ is $\mathrm{F}$, but also on the way of being $\mathrm{F}$ on which $a$ is $\mathrm{F}$ (because some ways are conducive to a given goal and some aren't). ${ }^{24}$ In other words, a given way in which an atomic proposition is true-i.e. the actual world's exact location in the set of truth-makers for $p$-although significant for deciding $p$ 's acceptability is irrelevant for its truth (as long as the actual world is located somewhere in the truth set).

In sum, after examining two types of semantic blindness the current proposal implies-one concerning the invariance of truth-conditions and other concerning goalsensitivity of acceptance- the error theory thus ascribed to competent speakers and thinkers who employ certain representations is explained by the facts of their practical rationality, and so deemed to be unproblematic. To a rational agent seeking to achieve a practical goal over-generating semantic competence is not necessarily an advantage. The truth is quite the opposite: for a practical success it may be necessary to turn the blind eye to what one's semantic competence legislates.

\footnotetext{
${ }^{22}$ By this I mean that both agents are au fait with this goal being at issue.

${ }^{23}$ Imagine that someone asks out of the blue 'Is the painted green leaf green?'. I suppose that the answer would always be 'yes' based purely on formal (i.e. type-1 analytic) properties of expressions, provided no pragmatic considerations are taken into account.

${ }^{24}$ When eliciting judgements of truth mentioning of the goals which would favour some ways of being $\mathrm{F}$ over the others should therefore be omitted. I thank an anonymous reviewer for inviting me to clarify my stance on the data for semantic theories.
}

\section{Conclusion}

In this paper I have presented a view on which linguistic and mental representation is both strongly compositional and occasion-sensitive. In response to Fodor's objection, I argued for an alternative interpretation of Travis cases to the one advocated by radical contextualists, and showed that to preserve the insight that what competent speakers and thinkers have in mind is occasion-sensitive it is not required to further assume that the content of their representations varies cross-contextually. We get intuitively correct predictions about these cases without having to assume that compositionally determined truth-conditions change. Instead I proposed that Travis cases and other similar examples that trade on context-shifting goals and purposes demonstrate that our readiness to accept certain true representations as true varies relative to which goal is contextually salient. The error theory that the current proposal entails is argued to be unproblematic insofar as it compensates for the over-generating nature of semantic competence, namely, the fact that not all of the representation's truth-makers are conducive to a given contextually salient goal.

Acknowledgements I would like to thank Alun Davies, Martin Stokhof, John Collins, Gareth Jones, Maria Serban, Adam Kimberley, Andrei Nasta, and Hiroshi Ohtani for comments on earlier drafts of this paper.

Funding This research is part of the project RContext Horizon 2020 Marie Sklodowska-Curie Actions funded by European Commission.

\section{Compliance with Ethical Standards}

Conflicts of interest The author declares that he has no conflict of interest

Open Access This article is distributed under the terms of the Creative Commons Attribution 4.0 International License (http://creativecommons.org/licenses/by/4.0/), which permits unrestricted use, distribution, and reproduction in any medium, provided you give appropriate credit to the original author(s) and the source, provide a link to the Creative Commons license, and indicate if changes were made.

\section{References}

Asher N (2011) Lexical meaning in context: a web of words. Cambridge University Press, Cambridge

Austin JL, Warnock GJ (1962) Sense and sensibilia, vol 108. Oxford University Press, Oxford

Borg E (2010) Meaning and context: a survey of a contemporary debate. In: Whiting D (ed) The Later Wittgenstein on Language. Palgrave, Basingstoke

Buekens F (2005) Compositionality, aberrant sentences and unfamiliar situations. In: Machery E, Schurz G, Werning M (eds) The compositionality of meaning and content: applications to linguistics, psychology and neuroscience. De Gruyter, Berlin, p 63 
Cappelen H, Lepore E (2008) Insensitive semantics: a defense of semantic minimalism and speech act pluralism. Wiley, New York

Carston R (2002) Thoughts and utterances: the pragmatics of explicit communication. Wiley, New York

Carston R (2010) Explicit communication and 'free'pragmatic enrichment. In: Soria B, Romero E (eds) Explicit communication. Springer, London, p 242

Carston R (2012) Word meaning and concept expressed. Linguist Rev 29(4):607-623

Dekker PJ (2014) The live principle of compositionality. In: Gutzmann D, Köppig J, Meier C (eds) Evaluations-Denotations-Entities: Studies on Context, Content and the Foundations of Semantics. Leiden, Brill

DeRose K (2006) bamboozled by our own words: semantic blindness and some arguments against contextualism. Philosophy and Phenomenological Research 73(2):316-338

Fodor JA (1990) A theory of content and other essays. MIT press, Cambridge

Fodor JA (2001) Language, thought and compositionality. Mind Lang $16(1): 1-15$

Fodor JA (2003) Hume variations. Cambridge University Press, Cambridge

Fodor JA (2008) LOT 2: the language of thought revisited. OUP, Oxford

Fodor JA, Lepore E (2002) The compositionality papers. Oxford University Press, Oxford

Grice HP (1975) Logic and conversation. Academic Press, New York, pp 41-58

Hansen N, Chemla E (2013) Experimenting on contextualism. Mind Lang 28(3):286-321

Hawthorne J (2004) Knowledge and lotteries. Oxford University Press, Oxford

Lahav R (1989) Against compositionality: the case of adjectives. Philos Stud 57(3):261-279

Lasersohn P (2012) Contextualism and compositionality. Linguist Philos 35(2):171-189

MacFarlane J (2005) The assessment sensitivity of knowledge attributions. Oxford Stud Epistemol 1:197-233

Montminy M (2009) Contextualism, invariantism and semantic blindness. Australas J Philos 87(4):639-657

Moravcsik J (1994) Is snow white? SYNTHESE LIBRARY, pp 71-71

Pagin P (2005) Compositionality and context. In: Preyer G, Peter G (eds) Contextualism in philosophy. Oxford University Press, Oxford, pp 303-348
Pagin P, Pelletier J (2007) Content, context and composition. In: Peter G, Preyer G (eds) Content and context. Essays on semantics and pragmatics. Oxford University Press, Oxford, pp 25-32

Partee BH (2010) Privative adjectives: subsective plus coercion. In: Bauerle R, Reyle U, Zimmermann TE (eds) Presuppositions and discourse: essays offered to Hans Kamp. Emerald, Bingley

Predelli S (2005) Painted leaves, context, and semantic analysis. Linguist Philos 28(3):351-374

Rancourt BT (2015) Epistemic relativism and semantic blindness. Synthese 192(3):859-876

Recanati F (2004) Literal meaning. Cambridge University Press, Cambridge

Recanati F (2007) Perspectival thought: a plea for (moderate) relativism. Oxford University Press, Oxford

Recanati F (2010) Truth-conditional pragmatics. Clarendon Press, Oxford

Recanati F (2012) Compositionality, semantic flexibility, and contextdependence. In: Hinzen W, Machery E, Werning M (eds) Oxford handbook of compositionality. Oxford University Press, Oxford, pp 175-192

Schoubye AJ, Stokke A (2016) What is said? Noûs 50(4):759-793

Searle JR (1980) The background of meaning. In: Searle J, Kiefer F, Bierwisch M (eds) Speech act theory and pragmatics. Springer, Dordrecht, pp 221-232

Sperber D, Wilson D (1986) Relevance: communication and cognition. Princeton University Press, Princeton

Stanley J (2005) Knowledge and practical interests. Clarendon Press, Oxford

Szabó Z (2010) The determination of content. Philos Stud 148(2):253-272

Travis C (1978) Meaning versus truth. Dialogue 17(03):401-430

Travis C (2000) Unshadowed thought: representation in thought and language. Harvard University Press, Cambridge

Travis C (2008) Occasion-sensitivity: selected essays. Oxford University Press, Oxford

Travis C (2009) Thought's footing: a theme in Wittgenstein's philosophical investigations. Oxford University Press, Oxford

Travis C (2011) Objectivity and the Parochial. Oxford University Press, Oxford

Westerståhl D (2012) Compositionality in Kaplan style semantics. In: Hinzen W, Machery E, Werning M (eds) The Oxford Handbook of. Compositionality. Oxford University Press, Oxford

Yablo S (2014) Aboutness. Princeton University Press, Princeton 